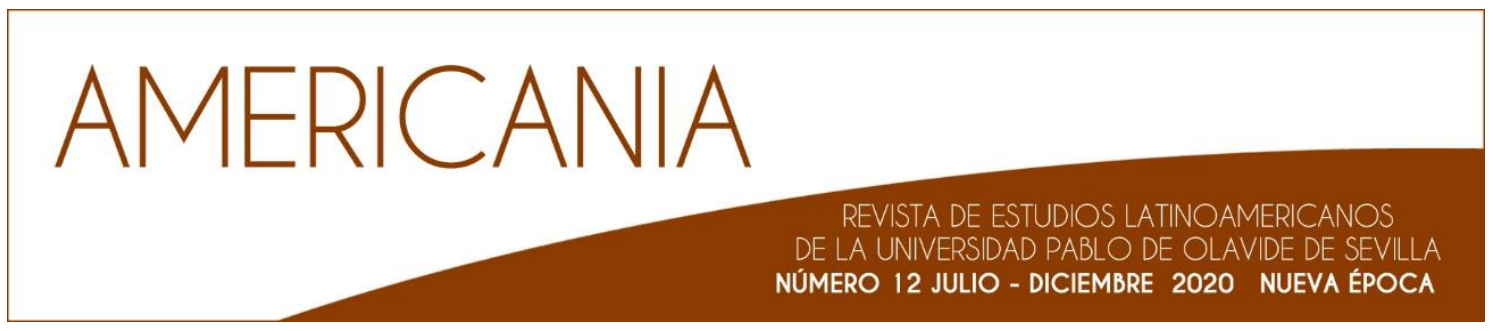

\title{
LAS ASOCIACIONES CASTELLANAS Y LEONESAS EN AMÉRICA COMO 'COMUNIDADES DE MEMORIA'
}

\author{
Espacios, Prácticas y Mediaciones
}

adacosta@usal.es

jblanco@usal.es

\author{
Arsenio Dacosta ${ }^{1}$ \\ Universidad de Salamanca \\ Juan Andrés Blanco 2 \\ Universidad de Salamanca
}

\section{Resumen}

Este artículo analiza las asociaciones fundadas por emigrantes castellanos y leoneses en América como 'comunidades de memoria', esto es, grupos humanos que se reconocen como afines en atención a un origen común percibido, en este caso, en relación con una región española de origen, Castilla y León. Para ello se analizan los símbolos y prácticas sociales que se desarrollan en las sedes asociativas como elemento central de dicha vinculación junto con la adscripción fundacional a una determinada localidad o provincia de aquella región. En este plano de resignificación han jugado un papel importante las relaciones establecidas con algunas instituciones españolas, como la universidad, las entidades locales o las instituciones regionales, mediadoras en la conformación de una 'ciudadanía castellana y leonesa en el exterior'. En este sentido se discute hasta qué punto dicha 'ciudadanía' puede considerarse una 'comunidad transnacional'.

\section{Palabras Clave}

Emigración - Asociacionismo - Identidad - Memoria - Castilla y León - América

1 Arsenio Dacosta es doctor en Historia por la Universidad de Salamanca y en Antropología Social y Cultural por la Universidad Nacional de Educación a Distancia (UNED). Ha sido docente en la Universidad de Alcalá de Henares y en el Departamento de Antropología Social y Cultural de la UNED en Madrid, e investigador invitado en la Universidade Nova de Lisboa, en la Universidad del País Vasco, en el Centro de Estudos da População e Sociedade de Oporto, y en la Universidad de La Habana. Especialista en Antropología Histórica, en los últimos años le ha preocupado la construcción de la memoria social en distintos periodos y contextos históricos. Actualmente es profesor titular en el Área de Antropología Social de la Universidad de Salamanca.

2 Juan Andrés Blanco Rodríguez es catedrático de Historia Contemporánea en la Universidad de Salamanca. Sus campos de especialización han sido la Guerra Civil española y los procesos migratorios contemporáneos, más específicamente, el asociacionismo migrante español en América. Dirige el Centro de Estudios de la Emigración Castellana y Leonesa vinculado al Centro Asociado de la UNED de Zamora, en su triple vertiente documental, divulgativa y científica. 


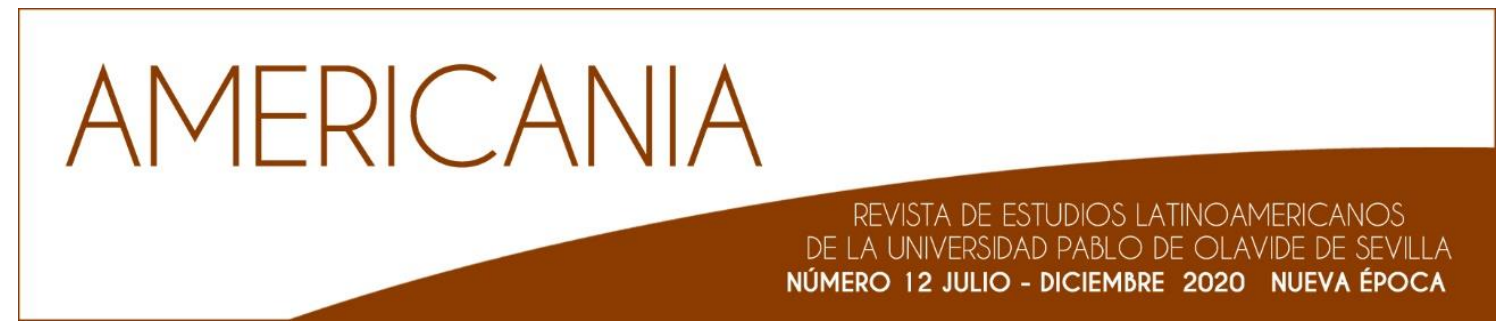

CASTILIAN AND LEONESE ASSOCIATIONS IN AMERICA AS 'COMMUNITIES OF MEMORY'

Spaces, Practices and Mediations

Abstract

This paper analyzes the associations founded by Castilian and Leonese immigrants in America as 'communities of memory', that is, human groups that recognize themselves as similar regarding a common origin. In this case, in relation to a Spanish region of origin: Castile and Leon. To this end, the symbols and social practices developed in the association's headquarters are analysed as a central element of this linkage, together with the foundational declaration of belonging to a specific locality or province in that region. The relationships established with some Spanish institutions have played an important role in this level of resignification. Among these we find the university, local entities or regional institutions, which mediate in the formation of a 'Castilian and Leonese citizenship abroad'. In this respect, it is discussed to what extent this 'citizenship' can be considered a 'transnational community'.

\section{Key Words}

Emigration - Associationism - Identity - Memory - Castilla and León - America 


\section{Introducción}

El objetivo de este trabajo ${ }^{3}$ es analizar el fenómeno de la emigración castellana y leonesa desde la perspectiva de la 'memoria colectiva', en la línea de lo ya expuesto en la introducción al presente dossier. Para ello analizaremos el fenómeno desde la perspectiva de la emigración que partió de las provincias que hoy conforman la región de Castilla y León, particularmente de sus comarcas más occidentales y septentrionales. Este fenómeno tuvo un impacto muy notable, intensificado en la oleada migratoria de los años 60 y 70, y que ha continuado hasta el presente; un fenómeno que donde tuvo más amplias y persistentes manifestaciones sociales e institucionales en su periodo clásico fue en los principales destinos migratorios de América, en las repúblicas de Cuba y Argentina. Desde la perspectiva de la sociabilidad migrante, la más lógica a la hora de abordar la cuestión de la 'memoria colectiva', nos interesa saber cómo se mantuvo y cómo se ha revitalizado desde finales del siglo pasado.

La interacción entre las sociedades fundadas en América por aquellos emigrantes (y sostenidas en la actualidad por sus descendientes) con las instituciones españolas surgidas de la Transición es el eje de nuestra argumentación, lo mismo que las materializaciones surgidas de dicha interacción. Desde la perspectiva aquí adoptada, la de la memoria, es importante analizar dicha interacción, dicho plano institucional, toda vez que la memoria, como la 'identidad', son procesos que en época contemporánea tienen al estado como uno de sus principales constructores y agentes. Si esta vertiente institucional explica la revitalización de unos determinados significados y prácticas de identificación en un momento concreto, el elemento estructural que lo sostiene no es otro que lo que llamaremos 'comunidades de memoria', esto es, aquello que liga a los emigrantes y sus descendientes con un pasado definido por el proceso migratorio, y con un presente que les vincula con una sociedad (en este caso la castellano y leonesa) y sus instituciones.

En primer lugar, abordaremos la cuestión identificando el contexto asociativo americano, cómo se articulan estas 'comunidades de memoria' entendidas, siguiendo lejanamente la clásica aportación de Halbwachs4, como aquellos grupos

3 Forma parte de los resultados del proyecto de I+D Las asociaciones en la emigración exterior española: del mutualismo a las comunidades transnacionales y virtuales, dentro del Programa Estatal de Fomento de la Investigación Científica y Técnica de Excelencia, subprograma Estatal de Generación del Conocimiento, ref. HAR2015-65760-P (MINECO/FEDER, UE).

4 Halbwachs, Maurice, La mémoire collective, Albin Michel, París, 1997. 
que reconocen compartir un pasado común y adaptan dicho reconocimiento a las condiciones de su presente5. En segundo lugar, atenderemos a las iniciativas mediadoras que desde Castilla y León han permitido crear nuevas relaciones y nuevos efectos sobre dichas comunidades. El objetivo final es valorar hasta qué punto las 'comunidades castellanas y leonesas en el exterior', como las define la legislación regional6, conforman algo parecido a una 'comunidad transnacional'7, algo que tiene cierto interés en la reciente historiografía en lo que se refiere a la resignificación étnica y agenda política de las comunidades migrantes ${ }^{8}$.

\section{Las asociaciones como 'comunidades de memoria'}

Asumiendo la aportación teórica que se ha planteado desde la historiografía? desde una perspectiva más antropológica el interés de estas 'comunidades de memoria' radica en su dimensión étnica, lo que nos lleva al terreno de las 'identidades' del que hablaremos después. Por ello, abordamos la cuestión desde la conformación de discursos y prácticas de identificación, esto es, entendiendo que la 'comunidad de memoria' lo es porque se alimenta de sentidos a través de la construcción material y simbólica de un 'nosotros'.

5 Bellah, Robert N. et al., Habits of the Heart: Individualism and Commitment in American Life, University of California Press, Berkeley, 1985. Baer, Alejandro "La memoria social: breve guía para perplejos," en Zamora, J. Antonio y Sucasas, Alberto, eds., Memoria, política, justicia. En diálogo con Reyes Mate, Trotta, Madrid, 2010, 131-148.

6 Ley 8/2013, de 29 de octubre, de la Ciudadanía Castellana y Leonesa en el Exterior.

7 Glick Schiller, Nina; Basch, Linda, y Blanc-Szanton, Cristina, "Transnationalism: A New Analytic Framework for Understanding Migration," Annals of the New York Academy of Sciences, Nueva York, 645.1, 1992, 1-24; Glick Schiller, Nina; Basch, Linda, y Blanc-Szanton, Cristina, "From Immigrant to Transmigrant: Theorizing Transnational Migration," Anthropological Quarterly, Washington D.C., 68.1, 1995, 48.

8 Morawska, Eva, "Immingrants, Transnationalism, and Ethnicization: A Comparison of This Great Wave and the Last," en Gerstle, Gary y Mollenkopf, John, eds., E pluribus unum? Contemporary and historical perspectives on immigrant political incorporation, Russell Sage Foundation, Nueva York, 2001, 175-212. Tsuda, Takeyuki, Strangers in the Ethnic Homeland: Japanese Brazilian Return Migration in Transnational Perspective, Columbia University Press, Nueva York, 2003. Portes, Alejandro y Fernández-Kelly, Patricia, eds., The State and the Grassroots: Immigrant Transnational Organizations in Four Continents, Berghahn Books, Nueva York, Oxford, 2015. Vega-Durán, Raquel, Emigrant Dreams, Immigrant Borders: Migrants, Transnational Encounters, and Identity in Spain, Rowman \& Littlefield, Lanham, 2016. Regan, Vera; Diskin, Chloé y Martyn, Jennifer, eds., Language, Identity and Migration. Voices from Transnational Speakers and Communities, Peter Lang, Oxford, 2016. Acebillo-Baqué, Míriam, "The agency of migrant associations: analysing the variation of migrant influence across transnational processes", tesis doctoral, Universitat Autònoma de Barcelona, 2019.

9 Aróstegui, Julio, "Generaciones y memoria. (Historia y recuerdo de la España conflictiva)," en Aróstegui, Julio ed., España en la memoria de tres generaciones: de la esperanza a la reparación, Madrid: Editorial Complutense, Fundación Largo Caballero, 2007, 26-48. 


\section{Los espacios de sociabilidad migrante: un análisis de caso}

Se ha prestado poca atención a las dimensiones materiales de estas construcciones identitarias cuando, en nuestro entender, es esta materialidad, junto a las relaciones sociales que las producen y se tejen en torno a ella, lo que articula dichas 'identidades'. Está, por ejemplo, la cuestión de las sedes de las asociaciones españolas en América, en algunos casos magníficas, como la del antiguo Centro Gallego, hoy Gran Teatro de La Habana. En el caso del asociacionismo castellano y leonés en América este patrimonio no es, ni de lejos, comparable al caso señalado ni al de las principales realizaciones de la emigración asturiana, como son el Centro Asturiano de México o la Casona de Solís de su homólogo en Buenos Aires ${ }^{10}$. De hecho, el único Centro Castellano de cierta entidad, el de Cuba, mantenía su sede en régimen de alquiler en el Palacio Villalba de la capital habanera. Aun así, las sedes de las asociaciones fundadas por emigrantes castellanos y leoneses tienen su valor, aunque aquí aludiremos a lo realmente relevante, su sentido cultural y su relevancia social. No podemos hacer un repaso sistemático, así que lo ejemplificaremos a través de la realización que quizá nació con más modestia, pero a la postre se ha convertido en la decana de las sedes del asociacionismo castellano y leonés, la del Club Villarino de La Habana.

Actualmente hay 'comunidades castellanas y leonesas en el exterior' en varios países latinoamericanos. En Brasil, Chile, Colombia, Guatemala y Uruguay son asociaciones de carácter regional nacidas en el presente siglo, y cuentan con sedes modernas. La Agrupación Leonesa de México, fundada en 1941, inauguró en 2013 su actual sede de $6.000 \mathrm{~m}^{2}$ que lleva el nombre de 'Casa de Castilla y León'. En Argentina se combinan asociaciones con un carácter similar, de reciente fundación (o refundación) como sucede en La Plata, Bolívar, Tres Lomas, Casbas, Santa Fe11, Coronel Dorrego, Mar del Plata y Bahía Blanca, todas ellas surgidas en las últimas

10 En el caso de la Casona de Solís la inspiración principal es el plateresco, concretamente la "fachada rica" de la Universidad de Salamanca (Morales Sarlo, $\mathrm{M}^{\mathrm{a}} \mathrm{Cruz}$, "El Centro Asturiano de Buenos Aires y la arquitectura neoespañola en el Plata," en Morales Sarlo, Ma Cruz y Llordén, Moisés, dirs., Arte, cultura y sociedad en la emigración española a América, Universidad de Oviedo, Oviedo, 1992, 57-82). Recientemente se ha hecho hincapié sobre la búsqueda de un estilo "neoárabe" en las realizaciones de la emigración española en América en el primer tercio del siglo XX, y su sentido en relación con la noción de "Hispanidad" (Gutiérrez Viñuales, Rodrigo, "Identidades españolas en América a través del arte y la arquitectura. Escenarios de entresiglos (1890-1930) y prolongaciones en el tiempo," Historia y Política, Madrid, no 36, 2016, 191-210.

11 La Comunidad Castellana de Santa Fe es un caso particular porque se funda en este siglo sobre el precedente de un Centro Castellano (1921), y admite entre sus socios a naturales o descendientes de Castilla y León y Castilla-La Mancha (Dacosta, Arsenio y Blanco Rodríguez, Juan Andrés. "De lo difuso a lo concreto: los procesos de identificación regional en el seno del asociacionismo migrante castellano y leonés en Latinoamérica," Journal of Iberian and Latin American Research: JILAR, Londres, vol. 25, no 1, 2019, 98-111). 
décadas ${ }^{12}$. El resto de asociaciones, junto con el Centro Castilla de Rosario, fundado en 1920, tienen un carácter histórico y radican en los límites de la ciudad de Buenos Aires: el Centro Burgalés, el Centro Región Leonesa, el Centro Maragato 'Val de San Lorenzo', el Centro Salamanca, el Centro Soriano Numancia y el Centro Zamorano. En Cuba solo tres de las sociedades disponen de sede: la de la Colonia Zamorana, en un magnífico local cedido en 2003 por la Oficina del Historiador de La Habana en la calle Muralla de la Habana Vieja, y la Agrupación de Sociedades Castellanas, que la tiene desde 2008 en la calle Neptuno de Centro Habana haciendo las veces de sede de todas las asociaciones cubanas salvo la aludida Zamorana y el Club Villarino. La tercera de las anunciadas es la del mencionado Club Villarino que tomaremos como estudio de caso porque su antigüedad y continuidad, así como su carácter microterritorial, permiten analizar en una escala muy pequeña, pero significativa, los procesos que aquí queremos abordar.

Desde su fundación, pero muy especialmente a mediados de la década de 1910, el Centro Castellano de La Habana, con el fin de aumentar su masa social y lograr mejores recursos para la interlocución con las instituciones locales españolas, comienza a promover entre sus afiliados la creación de 'clubes' que pudieran atraer a sus coterráneos. Así nacen algunas de las aún existentes sociedades castellanas y leonesas de Cuba o las ya extintas Unión Vallisoletana, Recreo Burgalés, Club Segoviano, la sociedad de Naturales de Ávila, el Club Riojano y el Club Madrileño, también surgidas bajo el paraguas del Centro Castellano ${ }^{13}$. En su mayor parte adquirieron un carácter provincial, pero también hay constancia de iniciativas microterritoriales como las sociedades Hijos de Buiza o Hijos de Cofiñal, además de la Colonia Fermosellana, en este caso en Santiago de Cuba. El Club Villarino pertenece a esta última tipología por su composición con naturales de la localidad salmantina de Villarino de los Aires ${ }^{14}$. Aunque no conocemos cuantitativamente el contingente de villarinenses que llega a Cuba durante el periodo denominado de 'emigración en masa', sabemos que fue muy numeroso. Se ha estimado que hacia 1915 residían en

12 A ellas se suma una también reciente -fundada en 2009- aunque de carácter provincial, la Casa de Palencia en Argentina, con sede en Buenos Aires.

13 Blanco Rodríguez, Juan Andrés, "El Centro Castellano en Cuba, 1909-1961," Studia Zamorensia, Zamora, 3, 1996, 159-212. Blanco Rodríguez, Juan Andrés, "Cincuenta años de Castilla en Cuba: el Centro Castellano (1909-1961)," Fuentes y documentos de la emigración castellana y leonesa, Zamora, 1.1, 2014, 5-44. Después volveremos a aludir a alguna de ellas.

14 La historia detallada de esta asociación ha sido recientemente analizada en Blanco Rodríguez, Juan Andrés; Sánchez Domínguez, Rubén y Dacosta, Arsenio, Un siglo de una asociación resistente: el Club Villarino de La Habana (19192019), Centro de Estudios de la Emigración Castellana y Leonesa, UNED Zamora, Zamora, 2020. 
el Reparto Almendares unos 60 villarinenses ${ }^{15}$ y otro núcleo quizá aún más amplio en el vecino barrio de Miramar, atraídos por las redes migratorias organizadas en torno a las oportunidades laborales generadas por otros paisanos en esta zona de La Habana ${ }^{16}$. Eran, sin duda, muchos más, y sabemos que mantenían estrechos los lazos de paisanaje y apoyo mutuo. En noviembre de 1919, durante la celebración de un bautizo, un grupo de naturales de aquella localidad acaricia la idea de organizar su propia asociación, algo que se sustancia oficialmente en apenas tres meses. No sabemos cómo pudo contribuir a esta fundación la crisis de la Unión Salmantina, sociedad que será refundada en 1922 como Colonia Salmantina de Cuba, pero el número de villarinenses fue suficiente para concretar la iniciativa. Hemos identificado a 217 fundadores de la sociedad, de los cuales tan solo cinco no nacieron en la localidad de referencia. Teniendo en cuenta el factor de masculinidad, las siempre problemáticas cifras de la emigración española y el intenso decrecimiento demográfico de la localidad salmantina entre las décadas de 1910 y 1920 (calculado en términos brutos en un 12,5\%), es posible que al filo de 1920 residieran en La Habana varios centenares más de villarinenses.

La sede propia, aspiración de toda asociación, llega algún tiempo después, y con no poco esfuerzo. El solar para la construcción se adquiere en 1928 y, en pocos meses, se ve levantada. Aunque se reformará y ampliará en varias ocasiones, el edificio social sigue casi cien años después en la calle $58 n^{\circ} 3301$ del actual municipio habanero de Playa. Diez años después, el Club consigue adquirir y levantar su panteón social en el Cementerio Colón de La Habana, asunto central para lo que nos ocupa. Finalmente, en 2007 la asociación recibe permiso para abrir un restaurante anexo a la sede social con el fin de ayudar al sostenimiento económico de la sociedad al estar orientado al mercado turístico.

Comenzaremos con algunas referencias a la sede social. Como decíamos, no ha cambiado mucho desde su fundación. Su fachada, presidida por un modesto pórtico, da paso a una gran sala despejada, pensada para acoger todo tipo de actos como asambleas o fiestas, además de las actividades sociales programadas por el

15 Sautié Mederos, Félix, dir., Las Sociedades Castellanas y Leonesas en Cuba: la huella de un siglo, 1909-2009, Junta de Castilla y León, Fundación Cooperación y Ciudadanía de Castilla y León, Valladolid, 2011, 303-304.

16 Se sigue así una constante en los procesos de emigración. En este caso el factor laboral tiene menos incidencia, aunque algunos de los socios destacados como José Grande, conocido como "el millonario chiquito", tendrán negocios en este Reparto de Almendares en los que estarán empleados algunos socios del Club (Blanco Rodríguez, Juan Andrés, "Emigración y asociaciones salmantinas en Cuba: el Club Villarino," Salamanca: revista de estudios, Salamanca, no 38, 1996, 160). 
Club. El mobiliario se coloca según la ocasión, pero permanece una sobria decoración a lo largo de las paredes. Esta decoración está compuesta por distintos emblemas cubanos y españoles, por reproducciones de fotografías de la historia del Club, algunos recuerdos y trofeos, y varias vitrinas antiguas procedentes del extinto Centro Castellano. Estas vitrinas datan del primer tercio del siglo XX y acogían los distintos estandartes bordados adquiridos por las asociaciones en España o regalados en algún caso por ayuntamientos o diputaciones provinciales. En el caso del Club Villarino, el estandarte actual es fruto de un encargo hecho por la sociedad a las Madres Adoratrices de la ciudad de Salamanca quienes lo bordaron en la década de 195017. Ese momento también se aprovechó para renovar las banderas cubana y española que presidían y siguen presidiendo la sede social.

Después aludiremos a este hecho porque queremos ahora detenernos en otros objetos con fuerte carga simbólica, como son algunos recuerdos de la localidad de origen, Villarino, incluyendo documentos enmarcados, fotografías o un sillar de granito labrado en Villarino y traído a Cuba en 1948 por uno de los directivos del Club. Estos objetos conforman una memoria gráfica y material de la sociedad, lo mismo que su archivo (situado en la planta alta del edificio) acoge la documentación societaria o el panteón los restos de muchos de sus asociados ${ }^{18}$. Su disposición nos habla de la conexión entre pasado y presente, del aquí (Cuba) y el allá (España), del sentido de la aludida comunidad de memoria. Junto a ellos, mencionábamos la existencia de algunas vitrinas procedentes del Centro Castellano, más concretamente tres 19 : la del Club Segoviano, la de una sociedad titulada 'Naturales de Ávila' y la del Club Madrileño que, a diferencia de las anteriores, aún conservan en su interior el estandarte bordado de aquella sociedad. En los tres casos, estos muebles y estandarte son prácticamente los únicos vestigios que se conservan de aquellas asociaciones. El resto de la serie de vitrinas y estandartes de las sociedades castellanas y leonesas se conservan en la actual sede de la Agrupación, así que el hecho de que parte de ellos se custodien en la sede del Club Villarino, más allá de su reutilización, nos habla del mantenimiento de un vínculo histórico con la que fue la matriz de todas ellas: el Centro Castellano de La Habana.

17 El Diario de La Marina de La Habana de 22 de agosto de 1953 refiere la recepción de dicho estandarte con ocasión de la fiesta patronal del Club.

18 Estos objetos y diversas imágenes de la sede pueden verse en los anexos de Blanco Rodríguez, Sánchez Domínguez y Dacosta, Un siglo de una asociación resistente: el Club Villarino de La Habana.

19 La cuarta vitrina es la que acoge el estandarte del Club Villarino y, aunque imita a las otras, parece posterior y carece de remate labrado que imita al escudo provincial. 


\section{La (re)significación identitaria en el seno del asociacionismo castellano y leonés}

Al entrar en la sede del Club Villarino, como en cualquier otra sociedad castellana y leonesa en América, no sorprende ver una bandera (o varias) de la comunidad autónoma de referencia junto a otros símbolos. Este uso es, obviamente, reciente por mucho que se identifique con un reino bajomedieval, la Corona de Castilla, cuyo ámbito pretérito y presente no coinciden en absoluto. Esta indefinición histórica, en sus dimensiones territorial y política, no impide que la vinculación exista en el presente. La razón, tal y como hemos defendido en algún trabajo reciente, es que la identificación con esta región (o con cualquier otra entidad institucional en el pasado o en el presente) se corresponde tanto con su dimensión discursiva como con las dinámicas de reconocimiento mutuo ${ }^{20}$. En el caso del Club Villarino, esta vinculación siempre se proyectó hacia la localidad de origen, siendo muy intensa hasta finales de los años 50 del pasado siglo. Fue entonces, entre finales de los 30 y finales de los 50 del pasado siglo, cuando los emigrantes oriundos de esta localidad salmantina ayudaron de forma decisiva al desarrollo de la misma financiando sus escuelas, obras en el cementerio e, incluso, la línea telefónica21.

La memoria de esa vinculación es palpable en la sede (por descontado en la documentación que se custodia su archivo) y también en el pueblo de origen que, ya en el presente siglo, ha comenzado a reforzar una vinculación debilitada a finales del pasado. En ningún momento de su historia el fuerte vínculo afectivo con esta localidad concreta fue contradictorio con la idea de pertenencia a la provincia de Salamanca, manteniendo una especial relación con la Colonia Salmantina de Cuba, y también con la Diputación Provincial de Salamanca. Esta adscripción múltiple continúa, y se suma hoy a la vinculación que se manifiesta con la región de Castilla y León. Por descontado, si algo caracteriza al asociacionismo castellano y leonés desde su origen es la ausencia de conflicto o, si se prefiere, la total complementariedad, entre el sentido de pertenencia local o provincial con el genéricamente español22. La

20 Blanco Rodríguez, Juan Andrés, "Desarrollo de la identidad regional: el asociacionismo español en Cuba," en Blanco Rodríguez, Juan Andrés y Dacosta, Arsenio, eds., El asociacionismo de la emigración española en el exterior: significación y vinculaciones, Sílex, Madrid, 2014, 129-150. Blanco Rodríguez, Juan Andrés; Dacosta, Arsenio y Sánchez Domínguez, Rubén, "Identidades en la emigración española a Iberoamérica," População e Sociedade, Oporto, 25, 2016, 27-63. Dacosta, Arsenio Dacosta, "¿ldentidades? Algunas reflexiones a partir la experiencia migratoria castellana y leonesa a América," en Blanco González, Juan Francisco ed., Identidad y género en Castilla y León, Diputación Provincial de Salamanca, Salamanca, 2017, 203-210.

21 Blanco Rodríguez, Sánchez Domínguez, y Dacosta, Un siglo de una asociación resistente: el Club Villarino de La Habana.

22 Blanco Rodríguez, Juan Andrés, "La controvertida identidad castellana y leonesa en la emigración a América," Americanía: Revista de Estudios Latinoamericanos, Sevilla, 7, 2018, 94-136. 
ausencia de una institución política regional hasta muy finales del siglo XX, junto con la identificación cultural entre lo 'español' y lo 'castellano', conforman lo que hemos denominado en alguna ocasión 'identidad difusa'23.

El asociacionismo castellano y leonés en América emula, en buena medida, lo que hacen otros colectivos regionales, especialmente gallegos y asturianos, como es bien visible respecto a la constitución de sociedades microterritoriales o del aludido Centro Castellano en el caso de Cuba ${ }^{24}$, y en ensayos similares como los que se producen en México en la misma época ${ }^{25}$. Sin embargo, también se mueve por impulsos y condicionamientos propios, entre los cuales, el más original es el de la aludida indefinición de su posición identitaria, particularmente la de carácter regional. Hasta la etapa de la Transición política de los años setenta del siglo XX en España, los emigrantes procedentes de aquella región encuentran grandes dificultades para definir una posición distinta a la identificación genérica de una difusa 'Castilla' con España. De hecho, la referencia a un ámbito leonés hasta esa época fue fundamentalmente cultural y con una demarcación territorial respecto al ámbito castellano sin unívoca definición ${ }^{26}$. En la España contemporánea, hasta la Transición posfranquista e incluso después, la provincia ha sido la clave a partir de la división establecida en 1833 por Javier de Burgos. Ni la región ni la comarca (ésta se encuentra en buena manera subsumida en la división en partidos judiciales también definida en aquella reforma decimonónica) tienen una significación destacable.

En la parte esencial de las viejas tierras que un día habían formado los reinos de Castilla y de León el movimiento regionalista está trufado de notables indefiniciones entre las que destacan la dificultad para elaborar un proyecto aparte de la identificación de Castilla con España y la indefinición territorial de sus

23 Dacosta, Arsenio, "Identidades anfibias: hacia una conceptualización de la identidad política en el macrotexto migrante español," Fuentes y documentos de la emigración castellana y leonesa, Zamora, 3.4, 2015, 5-9. Blanco Rodríguez, Dacosta, y Sánchez Domínguez, "Identidades en la emigración española a Iberoamérica". Blanco Rodríguez, Juan Andrés, "La controvertida identidad castellana y leonesa en la emigración a América," Americanía: Revista de Estudios Latinoamericanos, Sevilla, 7, 2018, 94-136.

24 Blanco Rodríguez, Juan Andrés, "Desarrollo de la identidad regional: el asociacionismo español en Cuba," en Blanco Rodríguez, Juan Andrés y Dacosta, Arsenio, eds., El asociacionismo de la emigración española en el exterior: significación y vinculaciones, Sílex, Madrid, 2014, 129-150.

25 Dacosta, Arsenio y Blanco Rodríguez, Juan Andrés. "De lo difuso a lo concreto: los procesos de identificación regional en el seno del asociacionismo migrante castellano y leonés en Latinoamérica," Journal of Iberian and Latin American Research: JILAR, Londres, vol. 25, n 1, 2019, 100 ss.

26 Blanco Rodríguez, Juan Andrés, "La controvertida identidad castellana y leonesa en la emigración a América," Americanía: Revista de Estudios Latinoamericanos, Sevilla, 7, 2018, 94-136. 
propuestas ${ }^{27}$. Más que la regional predominará como elemento aglutinador, por tanto, la identificación provincial, aunque también estará presente entre los emigrantes la vinculación al lugar concreto de origen y en algún caso la identidad comarcal. Esto último se produce entre contingentes que como el soriano en un primer momento y, sobre todo, el leonés, el zamorano y el salmantino, los más numerosos de entre los de la región, y dentro de ellos, con comarcas donde dicha emigración fue particularmente intensa. Es el caso de la Montaña, la Maragatería o El Bierzo, entre las comarcas leonesas, o Sanabria y los Arribes del Duero, comarca natural esta última que abarca toda la zona fronteriza de Zamora y Salamanca, como es el caso del aludido Club Villarino o de las diversas sociedades fermosellanas que se crearon en Cuba y en Buenos Aires.

Estas identificaciones diversas, yuxtapuestas, no fueron percibidas como contradictorias pero, como hemos dicho, tuvieron su reflejo en el mapa asociacionista conformado por los emigrantes castellanos y leoneses. Fuera del exitoso caso del Centro Castellano en Cuba, que en 1926 ya tenía 62 delegaciones en toda la Isla28, el resto de ensayos de sociedades regionales tuvo escaso éxito hasta el presente siglo. Ya hemos aludido a un par de ensayos en la capital mexicana, siendo el primero una refundación de una sociedad montañesa (de naturales de Laredo para más señas), y en todo caso emulación expresa del exitoso Centro Asturiano de México. Por ello no es de extrañar que ese primer ensayo se reconvierta sin problema en un Centro Español en 1911, como tampoco extrañará que el único centro regional de origen castellano y leonés netamente republicano, la Casa Castilla de Buenos Aires, fuera fundada en 1937 por dos pequeñas agrupaciones de emigrantes fieles a la República procedentes de Soria y de Logroño ${ }^{29}$. El caso, en el fondo, no es muy diferente al del primer Centro Castilla de Rosario (Argentina) que se constituyó en 1920 a partir de la unión de una sociedad salmantina y otra soriana, y acabó aglutinando también a procedentes de otras provincias de Castilla y León y de la actual Castilla-La Mancha. Esta naturaleza híbrida, en este caso expresa, es la del Centro Castellano de Santa Fe, fundado en 1921, con la finalidad de "agrupar a todos los castellanos residentes en

27 Blanco Rodríguez, Juan Andrés, “La formación de la identidad regional en el ámbito de la actual Castilla y León: un proceso problemático y con notables indefiniciones," en Blanco Rodríguez, Juan Andrés, coord., Regionalismo y Autonomía en Castilla y León, Junta de Castilla y León, Valladolid, 2004, 15-61.

28 Blanco Rodríguez, Juan Andrés, “Asociaciones castellanas y leonesas en América," en Blanco Rodríguez, Juan Andrés ed., El asociacionismo en la emigración española a América, UNED Zamora, Salamanca, 2008, 528.

29 Centro Documental de la Memoria Histórica (CDMH). Proyecto de Recuperación de Archivos del Exilio Español en la República Argentina. Centro Republicano Español (CRE)-Buenos Aires. Ref: ES.37274.CDMH/3.81.1. 
esta ciudad para organizar en un sitio apropiado los juegos y diversiones que en nuestra tierra hemos compartido en nuestra infancia y juventud, contribuyendo con esto a mantener más frescas en nuestra mente, los recuerdos y añoranzas de nuestra patria ausente"30. Existió un Centro Castellano en Córdoba, del que apenas tenemos noticias, y aún menos de otras efímeras sociedades como la Unión de Sociedades Castellanas, la Sociedad de Castellanos Unidos o el Centro Castilla de Buenos Aires ${ }^{31}$.

Podría pensarse que entre el asociacionismo leonés podría haberse dado un sentimiento contradictorio respecto de lo anterior por el mayor contingente de emigrantes y por la propia indefinición de lo 'castellano', pero nunca se dio más allá del aspecto nominal y de un carácter puramente cultural, muy ligado a particularidades de tipo folklórico y religioso32. Por ejemplo, el Centro Región Leonesa no fue propiamente, ni es, una entidad regional, sino provincial. Esta renuncia es expresa en su primer Reglamento donde se establece su carácter abierto al conjunto de españoles, ya que puede ser socio todo "Hijo o hija de español o española, nieto o nieta de español o española, madre, esposa, viuda de español que sea o haya sido socio"33. La idea de una región leonesa con Zamora y Salamanca pero sin Asturias y Galicia, no deja de ser una idea confusa y difusa en el competitivo mercado étnico bonaerense ${ }^{34}$. Por ejemplo, en 1952 en la revista León, órgano de expresión del Centro, además de llamar a la 'unión' de los emigrantes leoneses, un artículo de J. Arroyo identifica el 'Reino de León' con la provincia, mientras la sección 'Información Regional' abre sus noticias con una alusión a la "instalación de fábricas en la meseta castellana"35.

30 Sólo permitía la afiliación de "castellanos", entendiendo como tales los procedentes de las dos regiones de CastillaLeón y Castilla-La Mancha, incluyendo a los naturales de las provincias de Madrid, Logroño y Santander (Centro Castellano de Santa Fe, Libro de actas, 28 de agosto de 1921).

31 Blanco Rodríguez, Juan Andrés, "Asociaciones castellanas y leonesas en América," en Blanco Rodríguez, Juan Andrés ed., El asociacionismo en la emigración española a América, UNED Zamora, Salamanca, 2008, 559.

32 No obstante, lo nominal parece tener algún peso argumentativo en Salgado Fuentes, Javier, La evolución de la identidad regional en los territorios del antiguo Reino de León, Ediciones Universidad de Salamanca, Salamanca, 2016.

33 En el acta de inscripción se consigna el pueblo de origen y la provincia, señal de que se aceptaban a procedentes de fuera de la de León.

34 Moya, José C., Cousins and Strangers: Spanish Immigrants in Buenos Aires, 1850-1930, University of California Press, Berkeley, 1998. Fernández, Alejandro E. Un mercado étnico en el Plata. Emigración y exportaciones españolas a la Argentina (1880-1935), C.S.I.C., Madrid, 2004.

35 León, año XXIX, no 221, p. 6, 12-12 y 34, respectivamente. 
Más allá de este caso, ya estudiado36, el de la Agrupación Leonesa de México nos habla de un carácter netamente provincial37, por mucho que esta sociedad acepte llamar hoy a su sede 'Casa de Castilla y León en México'. El fenómeno es similar a otros documentados en Argentina, como el antiguo Centro Región Leonesa de Mar del Plata que, desde 1993, se denomina Centro Castilla y León. Este ajuste es reciente, reflejo del nacimiento de las instituciones autonómicas, y es el mismo que ha impulsado la creación de nuevas sociedades regionales en países donde nunca existieron, como la Casa de Castilla y León do Brasil, y sus homónimas de Chile, Colombia, Guatemala y Uruguay, ninguna anterior al presente siglo38. También forma parte de este movimiento la fundación de la Federación de Sociedades CastellanoLeonesas de la República Argentina a finales del pasado siglo o la reciente adición del adjetivo 'Leonesas' al nombre de la Agrupación de Sociedades Castellanas de Cuba, fundada en 1971 sobre los rescoldos del Centro Castellano de La Habana.

Ciertamente, no podemos desatender las dinámicas de representación política entre las asociaciones fundadas por emigrantes y las instituciones españolas, particularmente las autonómicas. Es lo que en las sociedades castellanas y leonesas de Cuba se denomina 'castellanidad', trasunto directo de la 'galeguidade' o la 'asturianía' de las sociedades hermanas fundadas por oriundos de aquellas regiones. A diferencia de las dos anteriores, que tienen una expresa correspondencia normativa ${ }^{39}$, en el caso de Castilla y León el reconocimiento institucional (y por lo tanto el acceso a ayudas de diverso tipo) no se ha concretado en ese constructo identitario sino en el de 'ciudadanía castellana y leonesa en el exterior' y, en lo que atañe al fenómeno asociativo el apelativo de 'comunidades'.

Esta reconfiguración de las prácticas de identificación se superpone con la que consideramos una de las principales peculiaridades del asociacionismo castellano y leonés, el predominio de las sociedades provinciales. Esto obedece, sin duda, a causas históricas, fundamentalmente por causa de contingentes menores de

36 Blanco Rodríguez, Juan Andrés, "La controvertida identidad castellana y leonesa en la emigración a América," Americanía: Revista de Estudios Latinoamericanos, Sevilla, 7, 2018, 94-136.

37 Ordóñez, Nélida Verónica, “Historia de la Agrupación Leonesa de México (1941-1988)," en Blanco Rodríguez, Juan Andrés ed., El asociacionismo en la emigración española a América, UNED Zamora, Salamanca, 2008, 275-298.

38 Dacosta, Arsenio y Blanco Rodríguez, Juan Andrés. "De lo difuso a lo concreto: los procesos de identificación regional en el seno del asociacionismo migrante castellano y leonés en Latinoamérica," Journal of Iberian and Latin American Research: JILAR, Londres, vol. 25, no 1, 2019, 98-111.

39 Respectivamente: Decreto $111 / 2015$, do 6 de agosto, polo que se aproba o Regulamento de organización e funcionamento do Consello de Comunidades Galegas, y Decreto 46/2019, de 21 de junio, por el que se aprueba el Reglamento de la Ley del Principado de Asturias 2/2018, de 23 de marzo, de los asturianos en el exterior y del reconocimiento de la asturianía. 
castellanos y leoneses y, sobre todo, por redes migratorias menos localizadas. También por las dinámicas de unificación de distintos colectivos locales o comarcales en sociedades mayores, caso por ejemplo del Centro Zamorano de Buenos Aires, surgido en 1956 de la fusión del Centro Fermosellano con el Centro Zamorano Regional Sanabrés ${ }^{40}$. En el caso que analizamos, como en un juego de muñecas rusas, estas 'identidades' se articulan y retroalimentan sin contradicción, pero sí sujetas a las dinámicas internas de cada sociedad. Si argumentamos esto es para evitar una correspondencia causal entre los aludidos procesos de reconocimiento con las prácticas y sentidos de identificación de las que hemos llamado 'comunidades de memoria' porque donde residen aquellas es en las prácticas (simbólicas o materiales, rituales o administrativas) que se generan en su seno.

\section{El sentido de comunidad: vínculos y prácticas compartidas}

En los ejemplos anteriores hemos ido viendo como lo discursivo o normativo, la idea e incluso la palabra, no son sino reflejo de agendas y prácticas sociales. El cambio de denominación de una sociedad, cuando no implica un problema para la comunidad que la sustenta, es sustituido por uno más inclusivo, pero también conocemos ejemplos de lo contrario porque las aludidas comunidades se nutren también de sus tradiciones. Tradiciones entendidas como aquello que consideran que les pertenece, que les distingue, que les hace seguir unidos.

Esta cuestión es tan válida para aquellas sociedades recién fundadas como para las ya centenarias. ¿Qué motivó, por ejemplo, la creación de la Casa de Palencia en Argentina, la benjamina entre las 31 sociedades castellanas y leonesas reconocidas por el gobierno regional? ¿Qué hace que persista la más veterana de todas, la Sociedad Castellana de Beneficencia, fundada en Cuba en 1885? En el primer caso, la propia asociación reconoce en su página web que fue a raíz de la primera 'Operación Añoranza' organizada por la Diputación de Palencia en 2008 cuando se gestó el proyecto asociativo ${ }^{41}$. Podríamos decir, como ya se ha hecho, que la memoria fue 'activada'42 y, también, que fueron las dinámicas generadas en

40 Blanco Rodríguez, Juan Andrés, “Asociaciones castellanas y leonesas en América," en Blanco Rodríguez, Juan Andrés ed., El asociacionismo en la emigración española a América, UNED Zamora, Salamanca, 2008, 550-551.

41 Disponible en: https://www.casadepalencia.com.ar/ (Consultado el 30/05/2020).

42 Monteagudo Robledo, José Ignacio, "La memoria activada," en Blanco Rodríguez, Juan Andrés ed., De Zamora a América. Memoria de la emigración zamorana I, Junta de Castilla y León, Diputación Provincial de Zamora, Caja España, Salamanca, 2007, 83-98. 
aquel encuentro las que provocaron la continuidad del vínculo o, si se prefiere, su institucionalización. En el caso cubano al que hemos aludido, hemos podido comprobar que no se trata, a pesar de todas las dificultades sufridas, de una de esas 'sociedades de vitrina' a las que aluden nuestros informantes cubanos 43 , sino que mantiene, con absoluta modestia, su actividad asistencial y su panteón, además de aportar dinamismo a la Agrupación de Sociedades Castellanas de Cuba. Puede parecer una obviedad, pero lo que ha generado la primera y sostiene a la segunda es lo mismo: la existencia de una comunidad auto-reconocida como tal. Dicho reconocimiento se sustenta, como decíamos, sobre las tradiciones y la adscripción: un socio del Centro Maragato Val de San Lorenzo asume el origen leonés de sus ascendientes y, desde luego, de la asociación a la que pertenece ${ }^{44}$. Más allá de esto, la comunidad se articula sobre prácticas; podría pensarse que el fenómeno es inverso, pero es cuando aquellas languidecen cuando desaparece la comunalidad y, con ella, la identificación, y no a la inversa ${ }^{45}$. Hay muchos tipos de prácticas que articulan la comunalidad y aquí solo habremos de mencionar algunas. Acabamos de aludir al marco referencial, ideológico, y antes al espacio físico donde se encuentra esta comunidad. Sin embargo, es en la socialización, en esas ideas, símbolos, espacios y prácticas compartidas, donde se conforma la identificación y donde se alimenta la comunidad de memoria.

Acabamos de aludir a una de las dimensiones más poderosas, la ideológica, en relación con las tradiciones y dinámicas (incluso institucionales) de las sociedades. Los estatutos y reglamentos, lo mismo que la decoración de la sede o el emblema, aportan contexto simbólico y normativo a las relaciones sociales. Entre las motivaciones de los fundadores y aquellos que hoy sostienen las asociaciones está la idea de ayuda mutua, que ha estado en el pasado y seguramente también en el presente asociada al desarrollo de agendas e intereses particulares. La publicidad de los negocios que aparecen en las revistas de las asociaciones nos permite rastrear a algunos de sus directivos y sus actividades económicas más allá del marco de la

43 Sociedades que solo existen nominalmente, que ya no mantienen actividad asociativa.

44 González, Pablo Alonso y Álvarez Domínguez, Juan Miguel, "El Centro Val de San Lorenzo en Buenos Aires: emigración e identidad en la Maragataría (León, España)," Studia Historica. Historia Contemporánea, Salamanca, 31, 2013, 219-243.

45 Un fenómeno observable en el seno del asociacionismo migrante español es la reconversión de algunas estas asociaciones en empresas de servicios turísticos o de restauración. 
comunidad46. Un tema recurrente en las investigaciones de los últimos años ha sido el del interés por la élite migrante, esto es, aquellos españoles con más éxito económico y cómo pudieron utilizar las asociaciones para su propia promoción social o su beneficio económico 47 .

Sin duda esto se dio, y algún tipo de interés reportaba a los dirigentes de las asociaciones el desempeño de sus funciones que, por lo general, no eran remuneradas, al menos no en el caso castellano y leonés. Sin duda, todo esto sucedió, pero también nos constan como contrapartida las innúmeras horas, el esfuerzo e, incluso, los recursos económicos destinados por estos mismos dirigentes para el sostenimiento de la actividad e incluso el patrimonio de las asociaciones. El aludido caso del Club Villarino, el último que hemos analizado en profundidad, habla expresamente de los préstamos sin interés de los socios más acomodados para la adquisición de terrenos, por no hablar de la dedicación de horas y materiales propios, gestiones, cesión de mobiliario o vehículos, etc ${ }^{48}$. El que quizá fuera más destacado dirigente asociativo castellano y leonés en Cuba durante el siglo XX, Francisco Sánchez Tamame, reconocía en sus memorias la dificultad de compaginar en algunos momentos de su vida la gestión del Centro Castellano con su dedicación profesional y empresarial ${ }^{49}$. Los beneficios de la representación societaria son indudables, pero siempre inestables y, sobre todo, útiles en los países de destino. El ejercicio de la presidencia de una sociedad pudo tener alguna ventaja en términos de visibilidad en relación con las autoridades locales y a las consulares, como lo tiene ahora, aunque posiblemente en menor medida que durante el periodo de 'emigración en masa'. Solo el contexto del proceso de nacionalización surgido tras la promulgación de la

46 García Álvarez, Alejandro y Blanco Rodríguez, Juan Andrés, Gestión económica y arraigo social de los castellanos en Cuba, Junta de Castilla y León, Valladolid, 2009. Blanco Rodríguez, Juan Andrés y García Álvarez, Alejandro, El legado de España en Cuba, Sílex, Madrid, 2015.

47 Fernández, Alejandro E., "Patria y cultura. Aspectos de la acción de la elite española de buenos Aires (1890-1920)," Estudios Migratorios Latinoamericanos, Buenos Aires, 6-7, 1987, 291-307. Núñez Seixas, Xosé Manoel, "Leadership ethnique, exil politique et ethnonationalisme chez les collectivités ibériques en Amérique Latine (1880-1960)," en Devoto, Fernando y González-Bernaldo, Pilar, eds., Émigration politique. Une perspective comparée. Italiens et Espagnols en Argentine et en France (XIXe - XXe siècles), L'Harmattan, París, 2001, 263-294. Cánovas, Marília Dalva Klaumann, "El Diario Español y las asociaciones españolas en São Paulo, en las primeras décadas del siglo XX," en Blanco Rodríguez, Juan Andrés ed., El asociacionismo en la emigración española a América, UNED Zamora, Salamanca, 2008, 389-422. González, Elda E., "La práctica asociativa de los españoles en Brasil: la preponderancia de los espacios étnicos nacionales frente a los regionales," en Blanco Rodríguez, Juan Andrés y Dacosta, Arsenio, eds., El asociacionismo de la emigración española en el exterior: significación y vinculaciones, Sílex, Madrid, 2014, 191-208.

48 Blanco Rodríguez, Sánchez Domínguez, y Dacosta, Un siglo de una asociación resistente: el Club Villarino de La Habana (1919-2019).

49 Sánchez Tamame, Francisco J., Memorias de mi vida, Blanco Rodríguez, Juan Andrés; Dacosta, Arsenio y Sánchez, Rubén, eds., UNED Zamora, Zamora, 2016. 
'Ley de Nietos' 50 en época reciente tuvo algún peso en este sentido, lo mismo que lo tiene hoy en términos de representación respecto de las autoridades de la región, particularmente la Junta de Castilla y León. Lamentablemente, la crisis económica de 2008 lastró la consolidación de muchos programas, y la crisis que tenemos en ciernes es poco halagüeña en lo que toca a las inversiones y ayudas para estas comunidades 51 , con lo que el potencial beneficio del ejercicio de cualquier cargo asociativo queda reducido frente a crecientes exigencias administrativas y las incertidumbres acerca del futuro de las sociedades.

Uno de los elementos que más importancia tiene en el sostenimiento de estas comunidades de memoria son las relaciones familiares que se tejen en torno a las mismas, muchas veces con un carácter transgeneracional. Una dirigente asociativa cubana, Lidia Domingo, vicetesorera de la Agrupación de Sociedades Castellanas de Cuba y directiva de la Sociedad Castellana de Beneficencia, nos señaló en cierta ocasión que "las sociedades son muy familiares"52. Y, efectivamente, es fácil encontrar este nexo genealógico: a veces, la participación activa en la sociedad es una suerte de misión encomendada por un progenitor involucrado en el nacimiento y gestión de la asociación. Es el caso de la familia Rabanillo ya que alguno de sus miembros ostenta la presidencia de la Colonia Zamorana de Cuba prácticamente desde 198453. Este hecho no es universal, pero sí es una constante: no pocos dirigentes actuales de las sociedades castellanas y leonesas son descendientes de fundadores y destacados dirigentes de aquellas, como le ocurre a Alfredo Francisco Miranda, actual presidente del Centro Zamorano de Buenos Aires, cargo que ya ocupó su padre. Caso muy similar es el de Julia Hernando, presidenta del Centro Burgalés de aquella misma ciudad, cuya abuela Constantina ya participaba en las actividades

50 Nombre popular que se da en América a la más conocida como “Ley de la Memoria Histórica” (Ley 52/2007, de 26 de diciembre, por la que se reconocen y amplían derechos y se establecen medidas en favor de quienes padecieron persecución o violencia durante la guerra civil y la dictadura).

51 "La Junta de Castilla y León recorta un 13,2\% las ayudas a las comunidades en el exterior cuando más las necesitan," Castilla y León Exterior, 26 de junio de 2020. Según esta fuente, la cantidad concedida en 2020 a, por ejemplo, la Agrupación Leonesa de México es de 3920 €; en 1997 la Junta de Castilla y León otorgó prácticamente el mismo importe nominal (500.000 pesetas) a esta asociación (Boletín Oficial de las Cortes de Castilla y León, de 19 de noviembre de 1997, p. 10554).

52 Entrevista. La Habana, 6 de diciembre de 2016.

53 Durante el bienio 1993-1995 fue presidente D. Manuel Iglesias Rodrigo, aunque acompañado en la directiva por varios miembros de aquella familia (Blanco Rodríguez, Juan Andrés et al., "Historia de la Colonia Zamorana de Cuba en el siglo XX," en Blanco Rodríguez, Juan Andrés; Fernández, Mạ Antonia y Rabanillo, Sergio, eds., La Colonia Zamorana de Cuba: historia, presente y futuro, Centro de Estudios de la Emigración Castellana y Leonesa, UNED Zamora, Zamora, 2015, 69). 
sociales hasta el punto que sus descendientes lo llaman "su segundo hogar" 54 . Son los padres, o los abuelos 55 , los que inscriben a sus hijos como socios, a veces nada más nacer, o quienes les llevan a participar de la vida social desde niños. En estos se proyectan actividades que, como el baile, trazan un vínculo entre el pasado y el presente, entre la aldea o la provincia de origen y el destino migratorio del antepasado. Los cuerpos de baile, irrenunciables en Cuba para toda sociedad fundada por emigrantes, se nutren de los nietos de los socios aún en la actualidad y, por lo general, todas las sociedades organizan regularmente jornadas o actividades específicamente diseñadas para niños y jóvenes.

Aparte de otros cambios culturales que pueden darse en cada caso y contexto concreto, en nuestra experiencia en todas las asociaciones castellanas y leonesas en América existe actualmente una gran preocupación por el envejecimiento de la masa social y de la dirigencia ${ }^{56}$. En realidad, la preocupación por la renovación generacional es común al conjunto de las sociedades fundadas por emigrantes españoles en América. Si tomamos el caso de Cuba, con los datos que manejamos y verificamos en nuestro trabajo de campo entre 2016 y 2018 , solo unas pocas están presididas por una persona menor de 30 años, que siempre es descendiente de emigrantes, como ocurre con las gallegas Sociedad Puentedeume y su Partido Judicial, la de Emigrados de Riotorto, o de la de Hijos del Ayuntamiento de Cedeira, todas ellas con sede en La Habana57. Las 'comisiones de jóvenes' y otras iniciativas bienintencionadas 58 , incluyendo intentos más bien tímidos por usar las redes sociales, no parecen suficientes para lograr la deseada renovación.

En la actualidad el fenómeno, obviamente, tiene otras dimensiones, distintas a la que pudo tener hace un siglo. El primer factor para lo que nos ocupa tiene que ver con la masa societaria, cuya composición es muy diferente a la de entonces, y también en el caso argentino, por la llegada de nuevos contingentes de emigrantes

54 Recogido en el relato de Angelita López Segura titulado "Historia por la cual los hermanos: Boni, Emilia, Pedro y Angelita López Segura, llegaron a la Argentina" (publicado en Blanco Rodríguez, Juan Andrés et al. (eds.), $V$ Premio Memoria de la Emigración Castellana y Leonesa, UNED Zamora, Junta de Castilla y León, Zamora, 2018, 137).

55 Sin salir de la misma familia: "Entre los tres distinguidos por cumplir 25 años de socios, estuvo Jimena, la hija de la presidenta Julia Hernando de Aguirre, quien expresó emocionada que el mérito es del abuelo de la jovencita que la anotó como socia del Centro Burgalés apenas nació. "El Centro Burgalés de Buenos Aires celebra San Pedro y San Pablo" (Castilla y León en el Mundo, 21 de julio de 2009).

56 Un análisis en: Ascanio Sánchez, Carmen et al., La población de mayores españoles en Cuba. Migraciones, bienestar y políticas sociales, Mercurio Editorial, Madrid, 2013.

57 Fuente: distintos números de Galicia en el Mundo, 2016.

58 Por ejemplo, el "Espacio Joven" que incluye la web de la Federación de Sociedades Castellanas y Leonesas de la República Argentina (https://casadecastillayleon.org.ar/. Consultado el 30/05/2020). 
a mediados del siglo XX. Por poner un ejemplo, el ya centenario Club Villarino de La Habana cuenta con más de 300 socios, de los cuales no queda ningún salmantino, aunque sí 105 nacionalizados de los cuales la mayor parte son hijos o nietos de villarinenses, aunque también los hay descendientes de Galicia e, incluso, uno de Extremadura y otro de las Islas Baleares ${ }^{59}$. El desafío en este plano, incluso para las más previsoras de estas asociaciones60, es dar continuidad a las mismas. El acceso de los jóvenes a las directivas es, sin duda, un elemento clave para dar solución al problema aludido, pero dicho acceso se sustenta necesariamente en la participación de los jóvenes en la vida asociativa y en la reformulación o debilitación del sentido de pertenencia. La primera de las cuestiones, la de la participación de los jóvenes en la vida societaria, está lastrada por razones estructurales, como la falta de fondos de las sociedades o las decisiones de los directivos mayores priorizando actividades con las que los jóvenes no se sienten especialmente conectados. Esto hemos podido constatarlo en nuestro trabajo de campo en Cuba, anotando el desanclaje entre jóvenes y mayores en el seno de las asociaciones. Por ejemplo, las actividades recreativas, en las que el baile y la gastronomía tienen un papel central, son bien aceptadas por los jóvenes, pero estos también declaran carecer de una gran capacidad de decisión sobre la programación de actividades ${ }^{61}$. Una participante de un grupo focal organizado a tal efecto expresó la cuestión en términos de instrumentalización:

"Entonces ellos [los presidentes de muchas sociedades] quieren a los jóvenes para hacer una actividad, pero no para dirigir. Por ejemplo, cuando dicen, "vamos a hacer un bailable, vamos a poner música española", y les proponemos vamos a mezclar, vamos a poner también música moderna, dicen «no, no, no...». Los jóvenes que participen en la conferencia, que participen en la misa... pero no que decidan"62.

59 En diciembre de 2016 de los 358 socios contabilizados, solo 71 de ellos eran jóvenes o adolescentes según datos ofrecidos por su presidente José López Botello.

60 Es el caso de la Colonia Zamorana de Cuba con 4 de sus 11 cargos directivos en edades inferiores a los 25 años en fecha reciente (Castilla y León Exterior, 13 de enero de 2017. Disponible en: https://www.espanaexterior.com/noticias/maria-antonia-rabanillo-continuara-al-frente-de-la-colonia-zamoranade-cuba-4. Consultado el 30/05/2020.

61 Cuestionario para jóvenes de la Agrupación de Sociedades Castellanas de Cuba. Respuesta \#35, 29 de agosto de 2019.

62 Grupo focal desarrollado en la sede de la Agrupación de Sociedades Castellanas de Cuba, 13 de diciembre de 2016. Testimonio del participante 11XX. 
En cuanto al sentido de pertenencia de estos jóvenes descendientes de castellanos y leoneses es obvio que se articula sobre las prácticas aludidas en el seno de las asociaciones, pero donde se genera, fundamentalmente, es en el seno familiar. Una participante en el aludido grupo de discusión señalaba la importancia de continuar las tradiciones familiares, incluso proyectadas hacia las sociedades, particularmente en el caso de fundadores o personas muy implicadas en su gestión:

"Yo empecé a escuchar, y bueno, mi abuelo era gallego y mi abuela de Cuba. Mi abuelo llegó a Cuba y fue fundador de la sociedad. Cobra mucha importancia seguir con la tradición familiar. Es una de las sociedades españolas más grandes que hay"63.

En ocasiones, esos vínculos se reconstruyen, como desvela otra participante:

"Los valores familiares yo los tengo de referencia de mi bisabuela, que no era española. Pero cuando me enteré de dónde había salido mi bisabuelo, de dónde provenía, me interesé. Lo importante es saber quién tú eres. Encontrar una manera de decir 'Yo soy cubana, pero también soy española'"'64.

Esa identificación se transfiere a un sentido de pertenencia que no se percibe por lo general conflictivo en el caso de los descendientes de españoles en América, pero al que se ha añadido un criterio externo como son las aludidas 'galeguidade', 'asturianía' o 'castellanidad'. Este sentido de pertenencia, hasta ahora aprendido en el seno familiar y proyectado en la actividad de las sociedades, ha pasado a ser un requisito administrativo para los colectivos descendientes de emigrantes en América.

Hemos aludido a las actividades de las asociaciones como el ecosistema donde se reproducen los sentidos de pertenencia de estas comunidades de memoria. No haremos un catálogo detallado de las mismas, aunque entre ellas encontramos fiestas más o menos fijas en el calendario anual, como las patronales, aniversarios y, más recientemente, la reproducción de la fiesta regional castellana y leonesa en abril. Los antiguos 'días de la raza' o de la 'hispanidad' son hoy sustituidos por estas otras festividades que aparecen en el calendario administrativo español. Lo importante del 'Día de Villalar' cuando se celebra en Mar de Plata o Guatemala es que se asume por parte de las sociedades como parte de su actividad principal y como elemento

63 Grupo focal desarrollado en la sede de la Agrupación de Sociedades Castellanas de Cuba, 13 de diciembre de 2016. Testimonio del participante 09XX.

64 Grupo focal desarrollado en la sede de la Agrupación de Sociedades Castellanas de Cuba, 13 de diciembre de 2016. Testimonio del participante 06XX. 
de reconocimiento hacia aquella otra comunidad, en este caso la región, con la que se mantienen vínculos de pertenencia.

Esta última festividad, junto con las tradicionales fiestas patronales de las sociedades (que generalmente coinciden con la de la localidad o capital de provincia de origen), son las que tienen mayor componente ideológico, pero a efectos de lo que nos ocupa, todas las actividades societarias articulan los mecanismos generadores de la memoria. Las que tienen un componente folklórico por su dimensión étnica, en la que no insistiremos, pero también el resto de actividades culturales, deportivas o festivas no directamente relacionadas con la localidad, provincia o región de origen. Todas aquellas actividades en las que se participa, todo aquello que se hace, se dice o se practica en la sede de la asociación o en el espacio habilitado para desarrollar aquellas, construyen la comunidad de memoria.

Hay un espacio más clave para la conformación de esta última, particularmente en el caso cubano: el panteón de la sociedad. La construcción de estos enterramientos colectivos en América fue propia del periodo de 'emigración en masa', por lo que son aquellas sociedades más antiguas, las cubanas, para las que tienen una mayor relevancia. En primer lugar, porque constituyen aún hoy una parte sustancial de su patrimonio compartido en beneficio de los socios y sus familias ${ }^{65}$. Por lo demás, el panteón es, en el caso cubano al menos, el único patrimonio inmueble del que disponen las sociedades, salvo el Club Villarino, propietario también de su edificio social. A la cuestión de la propiedad se une su valor como legado, y más teniendo en cuenta que el lugar donde se localizan estos panteones es el Cementerio Colón de La Habana, catalogado como monumento nacional y, no en vano, uno de los más bellos cementerios del mundo. Por descontado, en torno al panteón se articulan ideas religiosas que forman parte importante de aquello que los descendientes de los emigrantes consideran propio. Las creencias religiosas se asocian a las ya aludidas fiestas patronales y a los cultos asociados a las mismas (un determinado santo, tal devoción mariana). Esto es común a todas las sociedades americanas, pero especialmente importante en las de vinculación leonesa, caso de la Agrupación Leonesa de México, nacida en 1941 a partir de una cofradía religiosa dedicada a la Virgen del Camino, patrona de León, y lo mismo puede decirse de

65 Cuando en 1965 se disuelve la Unión Vallisoletana de Cuba, su medio centenar de socios se integra en la Sociedad Castellana de Beneficencia, aportando a la misma el derecho de uso del panteón de aquella (Blanco Rodríguez, Juan Andrés, "Asociaciones castellanas y leonesas en América," en Blanco Rodríguez, Juan Andrés ed., El asociacionismo en la emigración española a América, UNED Zamora, Salamanca, 2008, 547). 
otras como la Agrupación Leonesa de Puebla o el antiguo Centro Región Leonesa de Mar del Plata, hoy Centro Castilla y León66.

Por último, en el panteón (en tanto que monumento funerario nada menos) se materializa la memoria genealógica de la sociedad. Volviendo a un ejemplo ya citado, el del Club Villarino, en la memoria por la celebración de sus cinco primeros lustros de vida se recogerá una nómina de todos los inhumados en el panteón entre 1939 y 194467 . Este recordatorio expreso y material, común a todo el asociacionismo español en Cuba, se amplía a actos puntuales, con carácter anual o extraordinario68. Esta memoria genealógica, cuyo ámbito primario es familiar, tiene también una dimensión pública a la que haremos referencia enseguida en relación con otras formas de memorialización del pasado de estas sociedades, esto es, el pasado de los emigrantes que llegaron a América y las fundaron.

\section{La mediación institucionalizada de las 'comunidades de memoria'}

Las 'comunidades castellanas y leonesas en el exterior', como las define la legislación regional, han mantenido y mantienen diversos vínculos con Castilla y León. Vínculos personales y empresariales, materializaciones asociativas, proyectos formativos e intercambios simbólicos. Uno de los aspectos menos conocidos para el caso castellano y leonés es el de las realizaciones por vía de mecenazgo de aquellos emigrantes y sus sociedades en diferentes pueblos y ciudades de la región. Lo mismo que gallegos y asturianos, aquellos crearon escuelas y cementerios en sus localidades de origen, contribuyeron a sus comunicaciones y a dotarlas de infraestructuras básicas, repararon y embellecieron sus iglesias, y ayudaron a costear fiestas patronales. En un trabajo aún en elaboración, el censo de esas materializaciones asciende a más de medio centenar69. Esta memoria materializada es, en muchos casos, un patrimonio olvidado, y por lo tanto en riesgo, a diferencia de los programas

66 Blanco Rodríguez, Juan Andrés, "La controvertida identidad castellana y leonesa en la emigración a América," Americanía: Revista de Estudios Latinoamericanos, Sevilla, 7, 2018, 116-117.

67 Club Villarino, Bodas de plata, 1019-1944, Imp. Ant. De Valdepares, La Habana, 1944, p. 69.

68 Por su distinta conformación, las asociaciones en Argentina no erigieron panteones societarios, pero sí consta, incluso en fecha reciente, actos de homenaje en esos entornos, como es posible rastrear en la revista León del Centro Región Leonesa de Buenos Aires o como materializó el Centro Castellano y Leonés de Casbas con ocasión del centenario de la fundación de esa localidad en noviembre de 2011 (https://casadecastillayleon.org.ar/festejo-delos-100-anos-2011/ Consultado el 30/05/2020).

69 Una aproximación en lo que se refiere a las promociones escolares en Blanco Rodríguez, Juan Andrés y Sánchez Domínguez, Rubén, "Emigrantes castellanos y leoneses y educación," en Llordén, Moisés y Prieto, José Manuel, eds., El asociacionismo y la promoción escolar de los emigrantes del norte peninsular a América, Ayuntamiento de Boal, Boal, 2012, 223-250. 
de documentación y recuperación del mismo, que se ha hecho en comunidades autónomas vecinas. La segunda gran oleada migratoria, con Francia, Suiza y Alemania como destinos principales, ha oscurecido un tanto la memoria y las realizaciones de unos emigrantes que, por lo general, buscaron fomentar el desarrollo de sus localidades y comarcas. Solo unos pocos, como Pablo Díez y sus descendientes, han recibido el reconocimiento público en Castilla y León debido a su capacidad inversora y acciones concretas de mecenazgo 70 . Como decíamos, estas realizaciones son en su mayor parte desconocidas para los ciudadanos de la región $y$, en ocasiones, olvidadas por los socios de las asociaciones americanas que las promovieron.

Más allá de las iniciativas memorialísticas generadas por las propias asociaciones, ha habido otras que han contribuido a la activación de la memoria colectiva como la exposición Memorias de un sueño. La emigración castellana y leonesa a América, producida por la Junta de Castilla y León para ser exhibida entre 2010 y 2012 en México D.F., Buenos Aires y, finalmente, Burgos y Palencia71. Otros proyectos, como el del futuro Archivo-Museo de la Emigración aún no se han materializado, mientras la dimensión académica se consolida en 2011 con la creación del Centro de Estudios de la Emigración Castellana y Leonesa.

Gracias a muchos esfuerzos y a pesar de los olvidos, la vinculación entre estas asociaciones y la región ha aumentado exponencialmente en las últimas tres décadas y a ello han contribuido decisivamente lo que hemos denominado 'mediaciones institucionales'72. La creación de la autonomía generó la interlocución entre sus jóvenes instituciones y las veteranas asociaciones en América. Esa nueva relación tuvo un efecto dinamizador en el asociacionismo americano, generando incluso nuevas sociedades en países donde nunca existieron y, sobre todo, revitalizando algunas históricas, y contribuyendo decisivamente a la coordinación entre ellas a través, fundamentalmente, de la Federación argentina y la Agrupación

70 El leonés Pablo Díez Fernández fue el impulsor del Grupo Modelo de México. Gran mecenas en ese país y en su provincia de origen, a él se debe, entre otras, la erección de la Basílica de la Virgen del Camino cerca de León. Sus descendientes, cuyo interés se centra en la provincia de León, han promovido recientemente a través de la Fundación Cepa González Díez el Museo de la Emigración Leonesa (https://www.museoemigracionleonesa.org/ Consultado el 30/05/2020).

71 Blanco Rodríguez, Juan Andrés; Dacosta, Arsenio y Sánchez Domínguez, Rubén, eds., Memorias de un Sueño. La emigración castellana y leonesa a América [catálogo de la exposición], Junta de Castilla y León, Salamanca, 2011.

72 Dacosta, Arsenio, Castellanos y leoneses en América: narración biográfica y prácticas de identificación, Ediciones Universidad de Salamanca, Salamanca, 2020. 
cubana73. Esa interlocución, además de la directa entre cada asociación y las instituciones regionales o provinciales de referencia, ha sido la realmente efectiva frente al limitado alcance del Consejo de la Emigración de Castilla y León ${ }^{74}$. Las políticas regionales y sus efectos han sido más efectivos cuando se han concretado en ayudas directas a las asociaciones para infraestructuras y actividades, a las personas mayores y dependientes vinculadas a las mismas, o a los jóvenes de las sociedades para seguir estudios en las universidades de Castilla y León.

Antes de que estas y otras acciones se definieran en ambiciosos planes regionales 75 , instituciones regionales de otro nivel ya venían contribuyendo a la activación de esas 'comunidades de memoria' mediante otro tipo de ayudas y reconocimientos. Las ayudas, también directas, llegan particularmente a Cuba por parte de la Diputación Provincial de Zamora y después otras diputaciones y algunos ayuntamientos de la región durante el denominado 'Periodo Especial' hasta la actualidad. Dentro de estas acciones, las más influyentes en relación con el reforzamiento de vínculos a ambos lados del Atlántico han sido las denominadas 'Operaciones Añoranza', iniciadas por la institución provincial zamorana, seguida por otras entidades similares de la región e, incluso, de fuera de la misma ${ }^{76}$. Estas 'Operaciones' consisten en financiar una breve estancia vacacional de aquellos emigrantes castellanos y leoneses pertenecientes a la 'tercera edad' que no pudieron costearse un viaje a su localidad de origen. En Zamora, el programa se ha desarrollado de forma ininterrumpida desde 1995, y fue replicado ya en este siglo en Salamanca, León, Palencia y Burgos. Desde 2006 se inició en paralelo una iniciativa denominada 'Operación Raíces' destinada, específicamente, a jóvenes descendientes iniciándose de nuevo en Zamora con la ayuda de la Junta de Castilla

73 Esta última se fundó en Cuba en 1971 tratando de seguir la estela del Centro Castellano de La Habana (Blanco Rodríguez, Juan Andrés, "La controvertida identidad castellana y leonesa en la emigración a América," Americanía: Revista de Estudios Latinoamericanos, Sevilla, 7, 2018, 112). En cuanto a la Federación, surgió en 1990 con el apoyo de la Junta de Castilla y León para, según Alfredo Miranda, presidente del Centro Zamorano de Buenos Aires, "propugnar el agrupamiento para una acción cohesionada de todas las instituciones castellano-leonesas de la República Argentina" ("El Centro Zamorano tiene historia," Zamora, no 6, 1992, p. 11). No obstante, su actuación se circunscribe a la coordinación de iniciativas y la gestión de ayudas procedentes de la Comunidad Autónoma.

74 Este órgano consultivo fue creado en 2006 (Decreto 55/2006, de 31 de agosto, por el que se crea el Consejo de la Emigración de Castilla y León). Actualmente sus funciones las tiene asumidas el Consejo de Políticas Demográficas (Decreto 4/2015, de 15 de enero, por el que se crea y regula el Consejo de Políticas Demográficas).

75 Actualmente sigue en vigor el II Plan estratégico de la ciudadanía castellana y leonesa en el exterior 2015-2018, prorrogado por la administración regional hasta finales de 2020 (https://www.jcyl.es/web/jcyl/AdministracionPublica/es/Plantilla100Detalle/1248367026092/1248367026092/12 84258302437/Comunicacion Consultado el 30/05/2020).

76 En Asturias una iniciativa paralela se inició en el año 2008 (Boletín Oficial del Principado de Asturias, de 23/04/2008). 
y León77. En nuestra opinión, estos programas, modestos en cuanto a sus objetivos, han podido contribuir mucho más que otros a la conformación de esta 'comunidad de memoria'. La experiencia del emigrante $\mathrm{O}$ del descendiente retornado temporalmente a la región de origen ha provocado, sin duda, efectos multiplicadores en la memoria compartida sobre la experiencia inicial de personas (los emigrantes) ya desaparecidas en su mayoría.

Estos vínculos (re)creados tienen su reflejo en las actividades de las sociedades en América, particularmente las de Argentina y Cuba, donde el asociacionismo de carácter provincial se desarrolló. También en la expresión escrita de la memoria familiar y colectiva articulada en torno a los Premios Memoria de la Emigración. La promotora de esta iniciativa fue otra institución pública, la universidad, más concretamente el Centro Asociado de la UNED en Zamora78. Gracias a su vinculación con la Diputación Provincial de Zamora, este centro de educación superior venía interesándose por la presencia castellana y leonesa en América. En 2005 organiza el I Congreso sobre la Emigración Castellana y Leonesa, y también con el apoyo de la Diputación Provincial de Zamora y la Junta de Castilla y León, organiza una exposición y convoca el Premio Memoria de la Emigración Zamorana. Se buscaba desde la universidad contribuir a establecer vínculos entre las instituciones públicas referidas y lo que no mucho después pasarían a denominarse 'comunidades castellanas y leonesas en el exterior'. La inspiración de estos premios son las convocatorias que organizaron los sociólogos polacos de entreguerras con un fin similar: recoger relatos de vida como testimonios significativos de procesos sociales, en este caso la emigración a América79. Al éxito de esa primera convocatoria contribuyeron decisivamente la Colonia Zamorana de Cuba y el Centro Zamorano de Buenos Aires.

77 Junta de Castilla y León. Consejería de Presidencia. Notificación de 24/02/2015. Disponible en: https://www.jcyl.es/web/jcyl/AdministracionPublica/es/Plantilla100Detalle/1284403021221/_/1284406120159/C omunicacion Consultado el 30/05/2020. Desde 2018 la Junta de Castilla y León ha organizado su propio programa para jóvenes menores de 36 residentes en América Latina (4 de Argentina, 2 de Cuba, 1 de Chile, 1 de Guatemala y 1 de Uruguay), denominado "Programa Encuentro", con una duración de tres semanas inspirándose, posiblemente, en iniciativas de formación de cuadros directivos para las asociaciones americanas como la "Escuela de Asturianía" creada en 2001 por esta comunidad autónoma (https://www.emigrastur.es/pages/index/escuela Consultado el 30/05/2020).

78 Dacosta, Arsenio, "Recuperación, análisis y difusión de la experiencia migrante: el Centro de Estudios de la Emigración Castellana y Leonesa," en Blanco Rodríguez, Juan Andrés y Dacosta, Arsenio, eds., El asociacionismo español de una emigración diferenciada, Polifemo, Madrid, 2020, en prensa.

79 Monteagudo Robledo, José Ignacio, "Emigrar y escribirse. La escritura personal de la emigración castellana y leonesa a América," Studia Zamorensia, Zamora, 11, 2012, 29-43. Para el caso polaco, véanse: Chalasinski, Josef, "The Life Records of the Young Generation of Polish Peasant as a Manifestation of Contemporary Culture," en Bertaux, Daniel ed., Biography and Society. The Life History Approach in the Social Sciences, Sage, Londres, 1981, 119-131; y 
El proyecto después se ampliaría a toda la región, con diversas convocatorias, estando actualmente resuelta y en edición la correspondiente al VI Premio Memoria de la Emigración Castellana y Leonesa. El resultado material ha sido la recuperación de más de 300 relatos de vida producidos por emigrantes o descendientes de emigrantes castellanos y leoneses fundamentalmente en América, siendo una de las mejores colecciones europeas de su tipo. Lo que interesa destacar aquí es su contribución a la generación de los aludidos vínculos y, en qué medida, la iniciativa académica activa o genera los mismos, contribuye a la conformación de esa 'ciudadanía en el exterior'. El balance quizá sea precipitado, pero creemos que en estos 15 años los aludidos Premios han podido contribuir decisivamente a, primero, la visibilización de dichas comunidades en España; segundo, a la revalorización de su contribución a la historia y el patrimonio de esta región; y, finalmente, a la conformación de las aludidas 'comunidades de memoria', cuestión que abordaremos en la discusión final.

\section{Conclusiones}

A lo largo de las páginas anteriores hemos aludido a las sedes sociales de las asociaciones como espacios donde se han articulado, en algunos casos durante más de un siglo, comunidades de iguales, antaño emigrantes de origen castellano y leonés, hoy fundamentalmente sus descendientes. Hemos atendido a su dimensión fundacional orientada, generalmente, a la ayuda mutua donde la recreación de la localidad o provincia de origen otorga el marco para la generación de una comunidad. Una comunidad, la formada por los socios, sus familias y afines, que se articula sobre sus símbolos y prácticas, sobre las relaciones y actividades que se organizan en su seno. En este sentido, muchas sociedades se mantienen porque se han sostenido estas prácticas, más allá de la nominal adscripción territorial de la asociación. Esta adscripción, que es relevante en un plano ideológico, o si se prefiere 'étnico', solo cobra sentido cuanto se integra en las aludidas prácticas, y por cuanto implica de elemento diferenciador con otras asociaciones similares o con el conjunto de la sociedad receptora. Además de esto, hemos tratado de desvelar cómo en fecha más reciente han contribuido también a ello algunas instituciones desde España mediante normas, planes y acciones. Esta relación renovada, con sus límites y

Markiewicz-Lagneau, Janina, La naissance d'une pensée sociologique. Le cas de la sociológie polonaise entre les deux guerres, Éditions de la Maison des Sciences de I'Homme, Cambridge University Press, París, 1981. 
éxitos, ha ayudado a revitalizar e incluso ha generado nuevas 'comunidades castellanas en el exterior'. Esta acción externa tiene un carácter mediador con efectos internos en cada una de las sociedades, a efectos de su dimensión institucional y, también, del desarrollo de su comunalidad. Las ayudas directas, las 'Operaciones Añoranza' y los Premios Memoria de la Emigración, entre otras iniciativas, han ayudado a revitalizar los viejos vínculos entre las sociedades americanas y las provincias de donde partieron los emigrantes que las fundaron, y también ha generado un sentido de vinculación con la región, Castilla y León, históricamente inexistente o difuso, nunca contradictorio con la identificación con lo genéricamente español.

En este sentido, es difícil apreciar todavía si estas 'comunidades castellanas y leonesas' pueden llegar a ser una 'comunidad transnacional'. Existe, sin duda, una historia y un origen común percibido por dichas comunidades y, en menor medida, por el conjunto de la sociedad de la región. Sin embargo, su sostenimiento y desarrollo a ambos lados del Atlántico solo puede pasar por aquello que está en la esencia de la comunalidad: las prácticas sociales compartidas. 


\section{Referencias Bibliográficas}

Acebillo-Baqué, Míriam, "The agency of migrant associations: analysing the variation of migrant influence across transnational processes", Tesis doctoral, Universitat Autònoma de Barcelona, 2019.

Aróstegui, Julio, "Generaciones y memoria. (Historia y recuerdo de la España conflictiva)," en Aróstegui, Julio (ed.), España en la memoria de tres generaciones: de la esperanza a la reparación, Editorial Complutense, Fundación Largo Caballero, Madrid, 2007, 2648.

Ascanio Sánchez, Carmen et al., La población de mayores españoles en Cuba. Migraciones, bienestar y políticas sociales, Mercurio Editorial, Madrid, 2013.

Baer, Alejandro "La memoria social: breve guía para perplejos," en Zamora, J. Antonio y Sucasas, Alberto (eds.), Memoria, política, justicia. En diálogo con Reyes Mate, Trotta, Madrid, 2010, 131-148.

Bellah, Robert N. et al., Habits of the Heart: Individualism and Commitment in American Life, University of California Press, Berkeley, 1985.

Blanco Rodríguez, Juan Andrés, "El Centro Castellano en Cuba, 1909-1961," Studia Zamorensia, Zamora, 3, 1996, 159-212.

Blanco Rodríguez, Juan Andrés, "Emigración y asociaciones salmantinas en Cuba: el Club Villarino," Salamanca: revista de estudios, Salamanca, n 38, 1996, 131-168.

Blanco Rodríguez, Juan Andrés, "La formación de la identidad regional en el ámbito de la actual Castilla y León: un proceso problemático y con notables indefiniciones," en Blanco Rodríguez, Juan Andrés (coord.), Regionalismo y Autonomía en Castilla y León, Junta de Castilla y León, Valladolid, 2004, 15-61.

Blanco Rodríguez, Juan Andrés, "Cincuenta años de Castilla en Cuba: el Centro Castellano (1909-1961)," Fuentes y documentos de la emigración castellana y leonesa, Zamora, $1.1,2014,5-44$.

Blanco Rodríguez, Juan Andrés, "Desarrollo de la identidad regional: el asociacionismo español en Cuba," en Blanco Rodríguez, Juan Andrés y Dacosta, Arsenio (eds.), El asociacionismo de la emigración española en el exterior: significación y vinculaciones, Sílex, Madrid, 2014, 129-150.

Blanco Rodríguez, Juan Andrés, "La controvertida identidad castellana y leonesa en la emigración a América," Americanía: Revista de Estudios Latinoamericanos, Sevilla, $2018,7,94-136$.

Blanco Rodríguez, Juan Andrés et al., "Historia de la Colonia Zamorana de Cuba en el siglo XX,” en Blanco Rodríguez, Juan Andrés; Fernández, Ma Antonia y Rabanillo, Sergio, eds., La Colonia Zamorana de Cuba: historia, presente y futuro, Centro de Estudios de la Emigración Castellana y Leonesa, UNED Zamora, Zamora, 2015, 17-86.

Blanco Rodríguez, Juan Andrés et al. (eds.), V Premio Memoria de la Emigración Castellana y Leonesa, UNED Zamora, Junta de Castilla y León, Zamora, 2018. 
Blanco Rodríguez, Juan Andrés; Dacosta, Arsenio y Sánchez Domínguez, Rubén (eds.), Memorias de un Sueño. La emigración castellana y leonesa a América [catálogo de la exposición], Junta de Castilla y León, Salamanca, 2011.

Blanco Rodríguez, Juan Andrés; Dacosta, Arsenio y Sánchez Domínguez, Rubén, "Identidades en la emigración española a Iberoamérica," População e Sociedade, Oporto, 25, 2016, 27-63.

Blanco Rodríguez, Juan Andrés y García Álvarez, Alejandro, El legado de España en Cuba, Sílex, Madrid, 2015.

Blanco Rodríguez, Juan Andrés y Sánchez Domínguez, Rubén, "Emigrantes castellanos y leoneses y educación," en Llordén, Moisés y Prieto, José Manuel (eds.), El asociacionismo y la promoción escolar de los emigrantes del norte peninsular a América, Ayuntamiento de Boal, Boal, 2012, 223-250.

Blanco Rodríguez, Juan Andrés; Sánchez Domínguez, Juan Andrés y Dacosta, Arsenio, Un siglo de una asociación resistente: el Club Villarino de La Habana (1919-2019), Centro de Estudios de la Emigración Castellana y Leonesa, UNED Zamora, Zamora, 2020.

Cánovas, Marília Dalva Klaumann, "El Diario Español y las asociaciones españolas en São Paulo, en las primeras décadas del siglo XX," en Blanco Rodríguez, Juan Andrés (ed.), El asociacionismo en la emigración española a América, UNED Zamora, Salamanca, 2008, 389-422.

Chalasinski, Josef, "The Life Records of the Young Generation of Polish Peasant as a Manifestation of Contemporary Culture," en Bertaux, Daniel (ed.), Biography and Society. The Life History Approach in the Social Sciences, Sage, Londres, 1981, 119131.

Dacosta, Arsenio Dacosta, “¿Identidades? Algunas reflexiones a partir la experiencia migratoria castellana y leonesa a América," en Blanco González, Juan Francisco (ed.), Identidad y género en Castilla y León, Diputación Provincial de Salamanca, Salamanca, 2017, 203-210.

Dacosta, Arsenio y Blanco Rodríguez, Juan Andrés. "De lo difuso a lo concreto: los procesos de identificación regional en el seno del asociacionismo migrante castellano y leonés en Latinoamérica", Journal of Iberian and Latin American Research: JILAR, Londres, vol. 25, no 1, 2019, 98-111.

Dacosta, Arsenio, "Identidades anfibias: hacia una conceptualización de la identidad política en el macrotexto migrante español," Fuentes y documentos de la emigración castellana y leonesa, Zamora, 3.4, 2015, 5-9.

Dacosta, Arsenio, Castellanos y leoneses en América: narración biográfica y prácticas de identificación, Ediciones Universidad de Salamanca, Salamanca, 2020.

Dacosta, Arsenio, "Recuperación, análisis y difusión de la experiencia migrante: el Centro de Estudios de la Emigración Castellana y Leonesa," en Blanco Rodríguez, Juan Andrés, y Dacosta, Arsenio (eds.), El asociacionismo español de una emigración diferenciada, Polifemo, Madrid, 2020, en prensa. 
Fernández, Alejandro E., Un mercado étnico en el Plata. Emigración y exportaciones españolas a la Argentina (1880-1935), C.S.I.C., Madrid, 2004.

Fernández, Alejandro E., "Patria y cultura. Aspectos de la acción de la elite española de buenos Aires (1890-1920)", Estudios Migratorios Latinoamericanos, Buenos Aires, 67, 1987, 291-307.

García Álvarez, Alejandro y Blanco Rodríguez, Juan Andrés, Gestión económica y arraigo social de los castellanos en Cuba, Junta de Castilla y León, Valladolid, 2009.

Glick Schiller, Nina; Basch, Linda, y Blanc-Szanton, Cristina, "From Immigrant to Transmigrant: Theorizing Transnational Migration," Anthropological Quarterly, Washington D.C., 68.1, 1995, 48-63.

Glick Schiller, Nina; Basch, Linda, y Blanc-Szanton, Cristina, "Transnationalism: A New Analytic Framework for Understanding Migration", Annals of the New York Academy of Sciences, Nueva York, 645.1, 1992, 1-24.

González, Elda E., "La práctica asociativa de los españoles en Brasil: la preponderancia de los espacios étnicos nacionales frente a los regionales," en Blanco Rodríguez, Juan Andrés y Dacosta, Arsenio (eds.), El asociacionismo de la emigración española en el exterior: significación y vinculaciones, Sílex, Madrid, 2014, 191-208.

González, Pablo Alonso y Álvarez Domínguez, Juan Miguel, "El Centro Val de San Lorenzo en Buenos Aires: emigración e identidad en la Maragataría (León, España)," Studia Historica. Historia Contemporánea, Salamanca, 31, 2013, 219-243.

Gutiérrez Viñuales, Rodrigo, "Identidades españolas en América a través del arte y la arquitectura. Escenarios de entresiglos (1890-1930) y prolongaciones en el tiempo," Historia y Política, Madrid, no 36, 2016, 191-210.

Halbwachs, Maurice, La mémoire collective, Albin Michel, París, 1997.

Markiewicz-Lagneau, Janina, La naissance d'une pensée sociologique. Le cas de la sociológie polonaise entre les deux guerres, Éditions de la Maison des Sciences de I'Homme, Cambridge University Press, París, 1981.

Monteagudo Robledo, José Ignacio, "Emigrar y escribirse. La escritura personal de la emigración castellana y leonesa a América," Studia Zamorensia, Zamora, 11, 2012, 2943.

Monteagudo Robledo, José Ignacio, "La memoria activada," en Blanco Rodríguez, Juan Andrés (ed.), De Zamora a América. Memoria de la emigración zamorana I, Junta de Castilla y León, Diputación Provincial de Zamora, Caja España, Salamanca, 2007, 8398.

Morales Sarlo, Ma Cruz, "El Centro Asturiano de Buenos Aires y la arquitectura neoespañola en el Plata”, en Morales Sarlo, M ${ }^{\mathrm{a}}$ Cruz y Llordén, Moisés (dirs.), Arte, cultura y sociedad en la emigración española a América, Universidad de Oviedo, Oviedo, 1992, 57-82. 
Morawska, Eva, "Immingrants, Transnationalism, and Ethnicization: A Comparison of This Great Wave and the Last", en Gerstle, Gary y Mollenkopf, John, eds., E pluribus unum? Contemporary and historical perspectives on immigrant political incorporation, Russell Sage Foundation, Nueva York, 2001, 175-212.

Moya, José C., Cousins and Strangers: Spanish Immigrants in Buenos Aires, 1850-1930, University of California Press, Berkeley, 1998.

Núñez Seixas, Xosé Manoel, "Leadership ethnique, exil politique et ethnonationalisme chez les collectivités ibériques en Amérique Latine (1880-1960)", en Devoto, Fernando y González-Bernaldo, Pilar (eds.), Émigration politique. Une perspective comparée. Italiens et Espagnols en Argentine et en France (XIXe - XXe siècles), L'Harmattan, París, 2001, 263-294.

Ordóñez, Nélida Verónica, "Historia de la Agrupación Leonesa de México (1941-1988)", en Blanco Rodríguez, Juan Andrés (ed.), El asociacionismo en la emigración española a América, UNED Zamora, Salamanca, 2008, 275-298.

Portes, Alejandro y Fernández-Kelly, Patricia (eds.), The State and the Grassroots: Immigrant Transnational Organizations in Four Continents, Berghahn Books, Nueva York, Oxford, 2015.

Regan, Vera; Diskin, Chloé y Martyn, Jennifer (eds.), Language, Identity and Migration. Voices from Transnational Speakers and Communities, Peter Lang, Oxford, 2016.

Sánchez Tamame, Francisco J., Memorias de mi vida, Blanco Rodríguez, Juan Andrés; Dacosta, Arsenio y Sánchez, Rubén (eds.), UNED Zamora, Zamora, 2016.

Sautié Mederos, Félix (dir.), Las Sociedades Castellanas y Leonesas en Cuba: la huella de un siglo, 1909-2009, Junta de Castilla y León, Fundación Cooperación y Ciudadanía de Castilla y León, Valladolid, 2011, 303-304.

Tsuda, Takeyuki, Strangers in the Ethnic Homeland: Japanese Brazilian Return Migration in Transnational Perspective, Columbia University Press, Nueva York, 2003.

Vega-Durán, Raquel, Emigrant Dreams, Immigrant Borders: Migrants, Transnational Encounters, and Identity in Spain, Rowman \& Littlefield, Lanham, 2016. 